\title{
Menggunakan Cobit 4.1 Dan Balance Scorecard Untuk Merancang Tata Kelola Sistem Informasi
}

\author{
Nibras Faiq Muhammad', Kusrini ${ }^{2)}$, Asro Nasrini $^{3)}$ \\ ${ }^{1}$ Universitas Amikom Yogyakarta, ${ }^{2}$ Universitas Amikom Yogyakarta, ${ }^{3}$ Universitas Amikom \\ Yogyakarta \\ ${ }^{1}$ Sarirejo 2 Kotagede, ${ }^{2}$ Ngringin, Condongcatur, ${ }^{3}$ Depok, Sleman \\ 1nibras.1064@ students.amikom.ac.id, ${ }^{2}$ kusrini@amikom.ac.id, ${ }^{3}$ asro@amikom.ac.id
}

\begin{abstract}
Abstrak
Dalam perkembangan dunia teknologi saat ini pemerintah dalam rangka meningkatkan kualitas layanan publik secara efektif dan efisien dengan upaya menyelengarakan pemerintahan yang berbasis elektronik atau sering disebut E-Government yang tertuang pada Intruksi Presiden nomer 3 tahun 2003. Pada RSKIA XYZ memiliki masalah untuk meningkatkan efisiensi biaya pada infrastuktur setelah berbasis elektronik. Maka diperlukan pengukuran guna mengetahui tingkat kematangan objek tersebut pada kasus pengelolaan efisiensi biaya. Demi tercapainya visi dan misi sebuah lembaga dibutuhkannya Tata Kelola TI guna mengetahui sejauh mana pemanfaatannya. Evaluasi sangatlah penting dalam penerapan tata kelola TI guna mengetahui sejauh mana penerapan tata kelola yang baik pada lembaga. Penelitian ini akan menjelaskan bagaimana meningkatkan infrastuktur dan profitabilitas bisnis dari lembaga medis. Balance Scorecard adalah sebuah metode kerangka kerja untuk menilai kinerja sebuah organisasi. COBIT dan Balance Scorecard adalah kombinasi metode yang baik untuk sabagai patokan dalam hal Internal prespektif yang bisa menjadikan acuan manajemen sebuah lembaga untuk pembenahan khususnya dalam hal infrasturktur TI. Kajian tersebut akan memberikan cara untuk meningkatkan maturitas yang nantinya akan digunakan sebagai referensi dalam desain tata kelola TI berdasarkan praktik terbaik COBIT 4.1 .
\end{abstract}

Kata kunci: COBIT, Balanced Scorecard, Tata Kelola TI

\section{PENDAhuluan}

Mengenai "Kebijakan dan Strategi Nasional Pembangunan E-Government" yang diatur dalam Instruksi Presiden Nomor 3 Tahun 2003, dalam rangka penyelenggaraan e-government secara nasional, gubernur dan bupati / walikota harus mengambil langkah dan tanggung jawab sesuai dengan fungsi, wewenang dan tugasnya masing - masing. Egovernment merupakan upaya penyelenggaraan pemerintahan berbasis elektronik dengan tujuan meningkatkan kualitas pelayanan publik secara efektif dan efisien (Bahrawi, 2014).

Tata kelola yang baik akan memastikan terciptanya pemerintahan yang transparan, akuntabel, efisien dan efektif. Teknologi Informasi (TI) Kemajuana memberikan peluang yang banyak digunakan, termasuk di pemerintahan. Salah satu upaya untuk mewujudkan good governance adalah dengan penerapan e-government yang diharapkan dapat meningkatkan efisiensi, efektivitas, transparansi dan akuntabilitas pemerintahan (Purwanto, 2013).

Sesuai dengan "Instruksi Presiden No. 3 Mengenai "Kebijakan dan Strategi Nasional Pembangunan E-Government 2003", setiap gubernur dan bupati / walikota harus mengambil langkah-langkah yang diperlukan sesuai dengan tugas, fungsi dan kewenangan masing-masing. untuk melaksanakan pembangunan e-Government pada pemerintah di seluruh negeri (KOMINFO RI, 2011). Egovernment merupakan suatu pekerjaan pengelolaan pemerintahan berbasis elektronik yang bertujuan secara efektif dan efisien meningkatkan kualitas pelayanan publik (Bahrawi, 2014)

Mengingat semakin pentingnya peran TI dalam upaya peningkatan kualitas layanan, realisasi aplikasi TI kini menjadi kebutuhan setiap organisasi penyedia layanan publik dari tata kelola pemerintahan yang baik (good governance) (KOMINFO RI,2011). 
RSKIA XYZ merupakan salah satu organisasi pelayanan kesehatan yang tergabung dalam organisasi kemasyarakatan Bantul yang berbentuk RSKIA dan dikelola oleh Pemerintah Provinsi.

Dalam studi ini, penggunaan kerangka informasi dan tujuan pengendalian teknologi terkait (COBIT) untuk manajemen TI. Standar COBIT digunakan karena memiliki jangkauan manajemen yang luas dan proses yang sangat detail COBIT merupakan panduan terlengkap dan praktik terbaik untuk manajemen TI.

Dari 34 Proses yang dimiliki COBIT, penelitian ini menggunakan empat proses dari domain Monitor and Evaluate (ME), yakni proses Pengawasan dan Evaluasi Performa TI (ME1), Pengawasan dan Evaluasi Kontrol Internal (ME2), Memastikan Kepatuhan Terhadap Persyaratan Eksternal (ME3), dan Penyediaan Tatakelola TI (ME4). Analisa data mengacu pada Key Performance Indicator, key Goal Indicator, dan Level Maturity Model yang memiliki enam skala atau level kematangan ( Non-existent, Initial/Ad Hoc, Repeatable but Intuitive, Defined, Managed and Measurable, and Optimized).

Berdasarkan pertanyaan diatas, maka penulis bermaksud untuk merancang manajemen tata kelola TI dalam evaluasi yang dapat meningkatkan kinerja layanan dan menjadi pedoman dalam pengelolaan tata kelola TI RSKIA XYZ..

RSKIA XYZ termasuk salah satu dari sekian banyak pelayanan kesehatan organisasi kemasyarakatan Bantul yang berbentuk RSKIA, karena kepemilikan bentuk organisasi ini mengalihkan beban keuangan ke basis egovernment. Oleh karena itu, perlu dilakukan evaluasi biaya dan manfaat yang diperoleh saat melakukan konversi ke e-government. Dalam penelitian ini difokuskan pada proses COBIT 4.1, dan berdasarkan sudut pandang Balanced Scorecard maka ditentukan referensi dalam wawancara:

1. Internal perspective Balanced Scorecard dengan tujuan bisnis Lower process costs dan tujuan teknologi Acquire and maintain IT skills that respond to the IT strategy, dengan proses COBIT 4.1 AI3 dan AI5

2. Menjelaskan tingkat kematangan kedalam nilai maturity level.

3. Pada penelitian ini dilakukan pada RSKIA $\mathrm{XYZ}$

\section{METODE PENELITIAN}

a. Jenis, Sifat dan Pendekatan

Jenis penelitian ini adalah penelitian eksperimental. Menurut Tuckman (1982), penelitian eksperimental bertujuan untuk mengetahui pengaruh variabel tertentu terhadap variabel lain dalam kondisi yang dikontrol secara ketat. Selain itu menurut definisi Hadi (1985), penelitian eksperimental mengacu pada penelitian yang dilakukan untuk mengetahui akibat perlakuan yang sengaja diberikan oleh peneliti.

Penelitian eksperimental adalah metode penelitian yang dapat menguji hipotesis kausalitas dengan benar. Dalam studi eksperimental, peneliti memanipulasi setidaknya satu variabel, mengontrol variabel terkait lainnya, dan mengamati pengaruh satu atau lebih variabel dependen.

Metode dalam penelitian ini menggunakan metode kuantitatif yang artinya telah memenuhi semua persyaratan untuk pengujian kausalitas. Karakteristik penelitian eksperimental adalah menguji secara langsung pengaruh variabel terhadap variabel lain dan menguji hipotesis kausalitas.

\section{b. Alur Penelitian}

Pada penelitian ini terdapat langkah pokok dalam gambar alur penelitian pada Gambar 1.

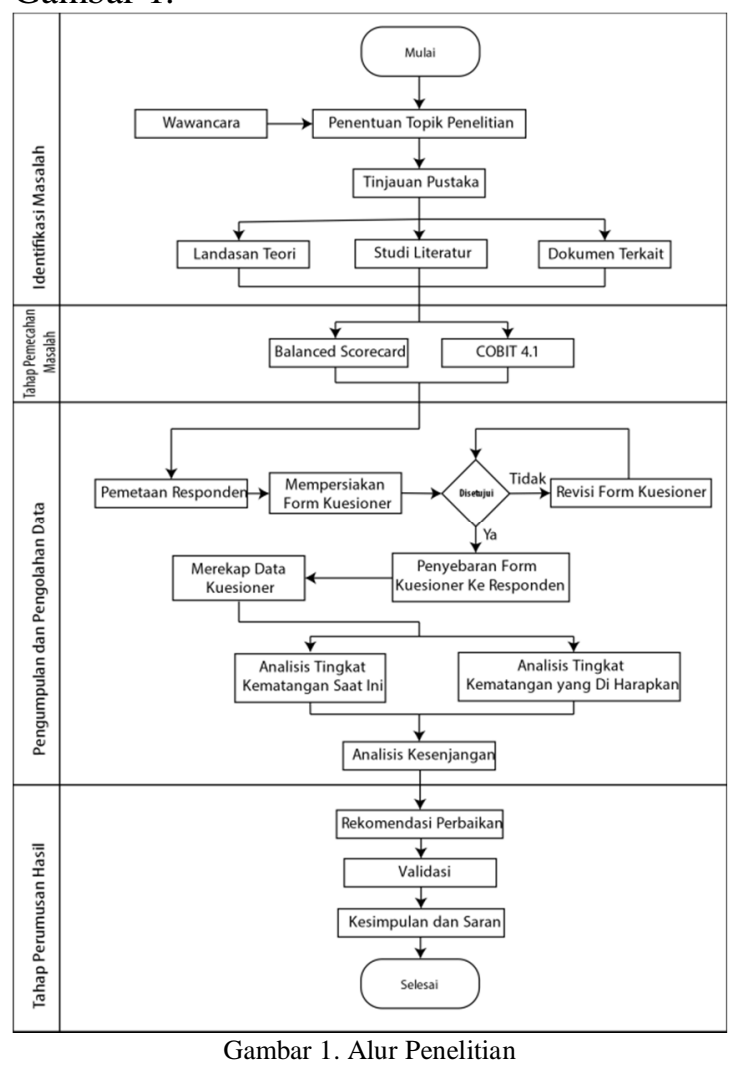




\section{ALUR PENELITIAN}

Metode penelitan yang ditetapkan ini disusun sesuai dengan kajian yang dilakukan pada saat pelaksanaan penelitian akan berjalan dengan baik.

\section{a. Identifikasi Masalah}

Tahapan ini merupakan tahap awal untuk menentukan topik penelitian yang diawali dengan wawancara dengan narasumber sasaran. Kemudian fokus pada tinjauan pustaka dari tiga aspek : landasan teori, penelitian pustaka dan literatur terkait.

\section{b. Tahap Pemecahan Masalah}

Pada tahap ini, setelah menemukan referensi dari tahap sebelumnya, digunakan metode COBIT 4.1 dan balanced scorecard untuk menyelesaikan masalah tersebut.

\section{c. Pengumpulan dan Pengolahan Data}

Ada beberapa tahapan pada tahap ini, pertama memetakan narasumber, kemudian menyiapkan kuisioner, jika tidak disetujui akan direvisi. Selain itu, jika disetujui, dibagikan kepada responden yang telah menyelesaikan pemetaan sebelumnya. Setelah data diperoleh, tingkat kematangan saat ini (as-is) dan tingkat kematangan yang diharapkan (to-be) akan dipahami melalui analisis kesenjangan.

\section{d. Tahap Perumusan Hasil}

Setelah memahami hasil dari tahapan ini, peneliti akan memberikan saran perbaikan berdasarkan masalah yang ditemukan, dan dapat melakukan perbaikan pada tujuan sebagai acuan perbaikan. Kemudian menarik kesimpulan dari hasil penelitian dan memberikan rekomendasi bagi peneliti selanjutnya

\section{HASIL DAN PEMBAHASAN \\ a. Domain Penelitian}

Berdasarakan dokumen yang telah didpatkan dari Rumah sakit XYZ dengan perspektif yang terdapat di Balance Scorecard (BSC), maka peneliti melakukan focus pada aspek Lower Proses Cost dalam prespektif proses Bisnis Internal pada BSC.

Lalu dilakukan pemetaan antara tujuan bisnis dengan tujuan teknologi informasi dari perspektif dalam internal yang mengacu pada kerangka kerja COBIT 4.1 agar domain proses terpilih dapat dilihat pada tabel 1

\begin{tabular}{|c|c|c|c|c|}
\hline \multicolumn{2}{|c|}{$\begin{array}{l}\text { Tujuan } \\
\text { Bisnis }\end{array}$} & No & Tujuan IT & $\begin{array}{c}\text { Proses } \\
\text { IT }\end{array}$ \\
\hline \multirow[t]{5}{*}{11} & \multirow[t]{5}{*}{$\begin{array}{l}\text { Lower } \\
\text { Proses } \\
\text { Costs }\end{array}$} & 7 & $\begin{array}{c}\text { memperoleh dan } \\
\text { memelihara sistem } \\
\text { aplikasi yang } \\
\text { terintegrasi dan standar }\end{array}$ & $\begin{array}{l}\mathrm{PO} 3, \\
\mathrm{AI} 2 \\
\mathrm{AI} 5\end{array}$ \\
\hline & & 8 & $\begin{array}{c}\text { memperoleh dan } \\
\text { mempertahankan } \\
\text { infrastruktur TI } \\
\text { terintegrasi dan standar }\end{array}$ & $\begin{array}{l}\mathrm{AI} 3, \\
\mathrm{AI} 5\end{array}$ \\
\hline & & 13 & $\begin{array}{c}\text { memastikan } \\
\text { penggunaan dan kinerja } \\
\text { aplikasi dan solusi } \\
\text { teknologi yang tepat }\end{array}$ & $\begin{array}{c}\text { PO6, } \\
\text { AI4, } \\
\text { AI7, } \\
\text { DS7, } \\
\text { DS8 }\end{array}$ \\
\hline & & 15 & $\begin{array}{c}\text { mengoptimalkan } \\
\text { infrastruktur, sumber } \\
\text { daya, dan kemampuan } \\
\text { TI }\end{array}$ & $\begin{array}{l}\text { PO3, } \\
\text { AI3, } \\
\text { DS3, } \\
\text { DS7, } \\
\text { DS9 }\end{array}$ \\
\hline & & 24 & $\begin{array}{l}\text { meningkatkan efisiensi } \\
\text { biaya TI dan } \\
\text { kontribusinya terhadap } \\
\text { profitabilitas bisnis }\end{array}$ & $\begin{array}{l}\text { PO5 } \\
\text { DS6 }\end{array}$ \\
\hline
\end{tabular}

Dari mengacu pada perspektif internal BSC, melakukan pengukuran tingkat kesesuain pada kendala yang terjadi pada organisasi yang ditunjuka pada tabel 2.

Tabel 2. Domain Kendala

\begin{tabular}{|l|l|l|}
\hline No & Kendala Sistem Informasi & Domain Proses \\
\hline 1 & $\begin{array}{l}\text { Minimnya keterlibatan dalam } \\
\text { manajemen Rumah Sakit saat } \\
\text { menentukan arahan, } \\
\text { kebijakan, strategi pada } \\
\text { pemanfaatan system informasi } \\
\text { rumah sakit dan aspek } \\
\text { pengendalian operasional }\end{array}$ & \\
\hline 2 & $\begin{array}{l}\text { Pada system informasi di } \\
\text { rumah sakit hanya melakukan } \\
\text { pengawasan saat ada laporan } \\
\text { keluhan dari pengguna }\end{array}$ & AI7, DS8 \\
\hline 3 & $\begin{array}{l}\text { Saat jam sibuk penggunaan } \\
\text { data yang padat pada server } \\
\text { menyebabkan respon menjadi } \\
\text { lambat dan lama berakibatkan } \\
\text { saat system pelayanan pada } \\
\text { bagian pendaftaran, kasir dan } \\
\text { farmasi lambat dalam } \\
\text { meperbarui data. }\end{array}$ & \\
\hline 4 & $\begin{array}{l}\text { Saat penginputkan data sering } \\
\text { terjadi kesalahan input oleh } \\
\text { pengguna }\end{array}$ & $\begin{array}{l}\text { AI4, PO2 } \\
\text { Tidak terdapat pengukuran } \\
\text { kinerja atau evaluasi dalam } \\
\text { pemanfaatan system informasi } \\
\text { secara khusus ada acuan dalam } \\
\text { pengelolaan kebijakan pada } \\
\text { system informasi secara } \\
\text { efeketif dan efisien. }\end{array}$ \\
\hline 5 & PO2, PO3, AI4 \\
\hline 6 & PO3 \\
\hline 5
\end{tabular}

Dari penjelasan masalah diatas yang sesuai domain yang telah dilakukan pada table 
2, lalu dapat ditarik sebuah kesimpulan bahwa evaluasi system infomasi pada rumah sakit kematangannya dapat dihitung menggunakan domain proses $\mathrm{PO} 2, \mathrm{PO} 3, \mathrm{AI} 2, \mathrm{AI} 4, \mathrm{AI} 7$ dan DS8

Domain pada proses PO2 ini tentang Menentukan Arsitektur Infomasi. PO3 tentang Menentukan Arah Teknologi. AI2 membicarakan tentang Memperoleh dan Memelihara Software. AI4 membicarakan tentang Memungkinkan Operasi dan Penggunaan aplikasi. AI7 membicarakan tentang Solusi Perubahan instalasi dan akreditasi. DS8 membahas tentang Mengelola Service desk dan Insiden.

\section{b. Daftar Responden}

RACI dapat mengkategorikan pada dalam kerangka kerja COBIT 4.1 sebagai peran ke semua proses IT yang mengacu pada kondisi yang sebenatnya pada Rumah Sakit XYZ yang di jelaskan pada Tabel 3

Tabel 3. Responden

\begin{tabular}{|c|c|c|c|}
\hline No & Respondent & Jabatan & $\begin{array}{c}\text { Jumlah } \\
\text { Responden }\end{array}$ \\
\hline 1 & CEO & $\begin{array}{c}\text { Wakil Direktur } \\
\text { Non Medis }\end{array}$ & 1 \\
\hline 2 & CFO & $\begin{array}{c}\text { Kepala Bagian } \\
\text { Keuangan }\end{array}$ & 1 \\
\hline 3 & CIO & Koordinator & 1 \\
\hline 4 & $\begin{array}{c}\text { Head } \\
\text { Development }\end{array}$ & Staf & 1 \\
\hline 5 & $\begin{array}{c}\text { Head } \\
\text { Operations }\end{array}$ & 4 \\
\hline \multicolumn{3}{|c|}{ Total Responden } & 1 \\
\hline
\end{tabular}

Dari penjelasaan table diatas, tugas masing masing responden seabgai berikut :

1. CEO yaiut sebagai wakil direktur non medis, yang mempunyai jabatan tertinggi membawahi semua direktorat non medis.

2. CFO dan CIO yaitu kepala bagian keuangan bertugas sebagai atasan dari tim EDP

3. Head Developtment data Processing yang bertugas dalam memelihara software, hardware dan mengolah data elektronik rumah sakit yang ada di system informasi rumah sakit.

\section{c. Analisis Tingkat Kematangan}

Berdasarkan hasil kuesioner, nilai tingkat kematangan tata Kelola system informasi saat ini dan yang diharapkan dapat dilihat dari selengkapnya pada tabel di bawah ini

Tabel 4. Analisis GAP

\begin{tabular}{|c|c|c|c|}
\hline Domain & $\begin{array}{c}\text { Kondisi } \\
\text { saat ini }\end{array}$ & $\begin{array}{c}\text { Kondisi yang } \\
\text { Diharapkan }\end{array}$ & GAP \\
\hline PO2 & 3 & 4,20 & 1,2 \\
\hline PO3 & 3,10 & 4,27 & 1,17 \\
\hline AI2 & 2,90 & 4,30 & 1,4 \\
\hline AI4 & 3 & 4,00 & 1,00 \\
\hline AI7 & 3 & 4,11 & 1,11 \\
\hline DS8 & 2,29 & 4,00 & 1.71 \\
\hline $\begin{array}{c}\text { Rata- } \\
\text { rata }\end{array}$ & $\mathbf{2 , 9 0}$ & $\mathbf{4 , 1 5}$ & $\mathbf{1 , 2 5}$ \\
\hline
\end{tabular}

Pada tabel diatas hasil perhitungan menemui nilai rata-rata kematangan tata Kelola IT pada RSKIA XYZ saat ini sebesar 2,90 atau dengan tingkat kematangan dilevel 3 (Defined). Sedangkan level kematangan yang diharapkan oleh pihak RSKIA XYZ adalah pada level 4 (Managed and Measurable). Nilai GAP ini diperoleh dari hasil pengurangan dari nilai kematangan yang diharapkan dengan nilai kematangan saat ini sebesar 1 .

Berikut presentasi dari hasil perhitungan level kematangan diatas menggunakan gambar agar lebih gampang dipahami.

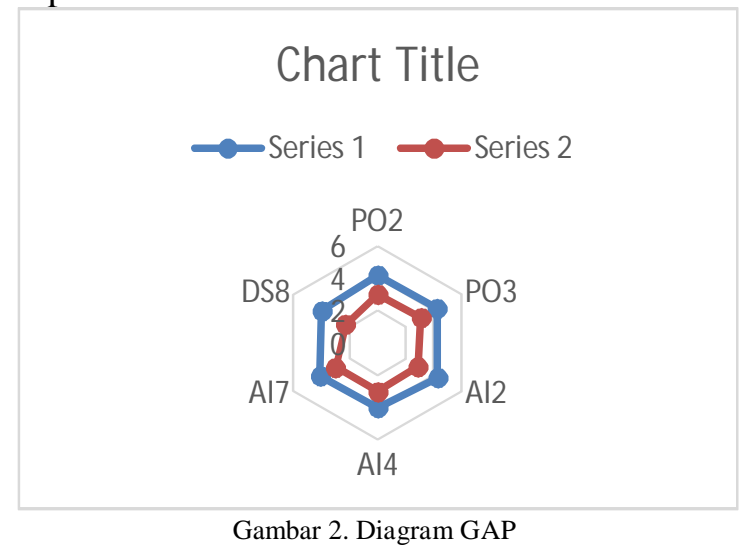

\section{d. Rekomendasi Perbaikan}

Dari hasil perhitungan tingkat keamanan semua domain proses TI terpilih, untuk mencapai tingkat kematangan yang diharapkan, perlu dirumuskan strategi perbaikan untuk masing-masing atribut keamanan, sehingga perlu dilakukan perbaikan dan penyempurnaan pada bidangbidang berikut, yaitu :

1. Kembangkan dokumen prosedural dan dokumen perencanaan untuk semua model arsitektur informasi. Memperkuat 
akuntabilitas (kejelasan, fungsionalitas, implementasi, dan akuntabilitas) dalam kinerja proses pengembangan arsitektur, dan menggunakan standar untuk mengukur keberhasilan arsitektur informasi agar mudah memantau kemajuannya

2. Dengan mempertimbangkan potensi dampak perubahan dan teknologi baru, serta dengan dukungan staf TI yang memiliki keahlian dan keterampilan untuk mengembangkan rencana infrastruktur teknis, memastikan bahwa rencana penggunaan teknologi untuk manajemen harus dikembangkan dan dipelihara. Tetapkan fungsi yang bertanggung jawab atas pengembangan dan pemeliharaan untuk mengelola pengembangan dan pemeliharaan rencana infrastruktur teknis

3. Metodologi formal yang mudah dipahami berupa dokumentasi sistem aplikasi dapat menentukan arsitektur dan spesifikasi aplikasi, termasuk proses perancangan, standar aplikasi, proses dan kualitas, serta dapat memelihara dan meningkatkan pengawasan dan pemeliharaan aplikasi. Sistem informasi rumah sakit.

4. Membuat buku pedoman dan perpustakaan formal, pengguna yang membutuhkan dapat mengakses informasi tentang materi pelatihan sistem informasi rumah sakit, dan meningkatkan kontrol kontrol untuk memastikan kepatuhan dengan standar, dan mengembangkan prosedur agar lebih sesuai untuk semua manual aplikasi

5. Beberapa program menggunakan metode khusus untuk mengevaluasi aplikasi yang diuji oleh manajemen. Untuk melakukan evaluasi secara rinci, manajemen harus memiliki indikator yang jelas pada saat evaluasi

6. Membuat prosedur laporan masalah formal dan berkala untuk diberikan kepada manajemen dalam bentuk laporan atau dokumen tertentu. Kembangkan metrik untuk mengidentifikasi masalah yang telah terjadi, dan evaluasi kinerja layanan dan buat layanan sistem bantuan yang sesuai.

\section{KESIMPULAN DAN SARAN}

Pada manajemen sistem informasi RSKIA XYZ RSKIA XYZ, pada proses IT yang dipilih nilai tingkat kematangan (yaitu $\mathrm{PO} 2, \mathrm{PO} 3, \mathrm{AI} 2, \mathrm{AI} 4, \mathrm{AI} 7$ dan DS8), PO2, PO3, AI2, AI4, AI7 dan DS8 adalah 2,90 atau
Tingkat kematangan adalah 3 (ditentukan). Hal ini membuktikan bahwa manajemen IT yang terorganisir berada pada tahap dimana walaupun manajemen belum terintegrasi sepenuhnya, telah berhasil membuat dan mengkomunikasikan standar manajemen standar untuk proses IT. Tingkat kematangan yang diharapkan atau yang akan datang adalah 4 (dapat dikelola dan diukur), yang merupakan tahap formal dan terintegrasi, dan terdapat beberapa indikator untuk mengukur kemajuan kinerja manajemen. Berdasarkan GAP yang ada, pengelola rumah sakit perlu meningkatkan saran guna meningkatkan kinerja atau kematangan sistem informasi manajemen RSKIA XYZ saat ini, sehingga dapat mencapai kematangan tujuan yang diharapkan.

Diharapkan manajemen RSKIA XYZ segera melaksanakan rekomendasi penerapan tata kelola sistem informasi yang terstandardisasi.

Penelitian selanjutnya tentang evaluasi sistem informasi RSKIA XYZ akan menggunakan metode Balanced Scorecard (BSC) dan sudut pandang lainnya guna mengevaluasi cakupan dengan menggunakan satu proses, sehingga cakupan proses TI yang dipilih menggunakan COBIT 4.1 lebih luas.

\section{REFERENSI}

Azizah, N., 2017 Audit Sistem Informasi Menggunakan Framework Cobit 4.1 Pada E-Learning Unisnu Jepara, Jurnal Simetris , Issn: 2252-4983, Vol 8 No 1.

Santoso. B. P., Hariyanti E., Wuryanto E., 2016 Penyusunan Panduan Pengelolaan Keamanan Informasi Untuk Firewall Configuration Berdasarkan Kerangka Kerja PCI DSS v.3.1 dan COBIT 5". Journal of Information Systems Engineering and Business Intelligence, e-ISSN 24432555, Vol. 2, No. 2.

Mustofa S. W., Handani., 2017 Pengukuran Kinerja Sistem Informasi Tata Kelola Keuangan Kantor Kecamatan Kemranjen Kabupaten Banyumas Menggunakan Framework Cobit 5.0 Pada Domain Mea (Monitor, Evaluate, And Assess), Jurnal Pro Bisnis, Issn : 1979 - 9258 E-Issn : 2442 - 4536, Vol. 10 No. 2. 
Jurnal Informa : Jurnal Penelitian dan Pengabdian Masyarakat. p-ISSN : 2442-7942, e-ISSN 2716-5051

Volume 7 Nomor 1 Juni 2021

Jayaraman S., 2013 When and How to Migrate to COBIT 5". COBIT focus, Volume 3

Radliya N. R., 2014 Audit Sistem Informasi Manajemen Rumah Sakit (Studi Kasus Pada Rsud Kota Tasikmalaya). [Thesis]. Bandung: Universitas Komputer Indonesia.

Hartono J., Abdilla W., 2011 Sistem Tata kelola Teknologi Informasi. Penerbit Andi, Yogyakarta

Gondodiyoto S., 2007 Audit Sistem Informasi + Pendekatan Cobit, Mitra Wacana Media, Jakarta.

Information Technology Governance Institute, 2007, COBIT 4.1: Framework, Control Objective, Management Guidelines, Maturity Models, IT Governance Institute, Rolling Meadows 